way back, the little cows have a hard time of it at the first and when they are few, for no sooner is one pretty creature fairly established in the station of male number one, who has got her there, than he perhaps sees another of her style in the water from whence she has come, and he devotes himself to coaxing the later arrival by the same winning methods so successful before; whereupon bull number two, one station in the rear, observing bull number one to be off guard, reaches out with his long, strong neck, picks up the passive cow by the scruff of her neck, just as a cat does a kitten, and deposits her upon his ground; and this will happen again and again until the little cow will finally find herself several stations back. Her last lord not being exposed to the same temptations as lie on the water level, gives her such care that not only could she not leave if she wished, but no other bull gets a chance of seizing her. When the females have all landed and the harems are full, it would seem that those nearest the water may contain on an average from fifteen to twenty females, those in the rear from five to twelve. The courage of the fur seal is of the highest order. As regards man, it is invariably of a defensive character. Though always on the defensive, he never retreats, but he will not attack ; the cows, however, are easily frightened and are timorous. Shortly after the females are landed, the young are born; they are for the first three months of a jet black colour, are about fourteen inches long, and weigh about four pounds. It would seem that they are nursed only every second day, the mothers going off to the fish grounds to get a supply of food, but they may also return to suckle their young at night. When returning in the daytime, each mother at once recognises her own young, though there may be thousands upon thouands all together blaating at once. Before entering into such a crowd, the mother stops and calls out, just as a sheep does for a lamp, and out of all the din she then recognises her offspring's voice, and makes direct for it ; but it would seem that the young ones do not of ten know their own mothers.

Early in August the young seals, now about six weeks old, are taught to swim. If dropped into deep water about this period down goes their bullet-like head, and they are drowned; at first they try their skill in the shallow pools, for a week or two they only flounder about, thrashing the water as little dogs will do. When for the first time they are well launched out they soon turn to the shore, and if by some receding wave they should be left high and dry, they will crawl away for a little distance and, quite exhausted, will coil themselves up to take a short recuperative nap, and then to the swimming lesson again. Once boldly swimming they seem to fairly revel in it. The parents do not in the slightest degree supervise or direct the young in swimming. The young shed their black coat about the middle of October; the second or sea-going jacket, does not at first vary in colour between the sexes, nor does a pronounced difference take place until after the third year. The females bear their first young when they are three years old, and the period of gestation lacks only a few days of a year.

The great herds of "bachelor" seals, numbering perhaps one-third to one-half of the whole aggregate of the 5,000,000 seals known to the Pribylov group, are never allowed under the pain of death to put their flippers on or near the rookeries. These are the seals of most importance to commerce, for with the exception of a few thousand young ones and an odd old male, these are the only ones slaughtered for their hides. They locate them in immense tracts, mostly away from the rookeries, but sometimes the road to these will pass along or through a rookery, where, as Iong as the bachelors keep to the main road, they are never molested; but if they pry about, it is all over with them, for they are literally torn to pieces. These bachelors are wonderfully gentle, but they are possibly the most restless animals in creation, they never seem quiet, not even in their sleep, they do not fast, as they constantly leave the land for the sea, though this at irregular periods depending a good deal on the weather; on land they sport and roll about as if in perfect enjoyment, curling and uncurling themselves, in fact they seem to be surcharged with a quite joyous life, but when in play they never grovel or bite or seem to show even an angry feeling. It is we have seen very different with them when they are a little older and begin to take upon themselves the cares of a harem. These seals pass a deal of their time in the water, where their gambols are truly wonderful, and the time they can remain under water is, Mr. Elliott writes, "past belief." They are readily, when on land, classified as to age. They shed their fur and hair during August. Passing over a detailed and well illustrated account of the various rookeries, carefully calculated as containing some $3,193,042$ breeding seals and their young in 1873, and of non-breeding seals over $\mathbf{r}, 500,000$, and the speculations as to the vast amount of fish consumed by this immense army, we have to notice briefly the chapter on the taking of the seals. Except for food, none but the "bachelors" are slaughtered when their furs are in good trim : the natives get between a herd and the sea, and then gently drive it up to a slaughtering station. In cool and moist weather the seals can be safely moved along at the rate of half a mile an hour; on firm grassy ground three or four men can secure and guide as many as a thousand seals at the same time. They are permitted frequently to halt, rest, and cool, as over heating injures their fur, and so on they go to death, and to supply with their hides the markets of the world. They never show fight, and are as docile as a flock of sheep; the bull seals on the contrary will fight rather than endure the panting torture of travel, so that if any of them get mixed up with a herd of bachelors they are easily let drop out; their fur is of no value. On arriving at the slaughter places the herd is allowed to cool, and then the killing begins ; the labour of skinning is severe and trying even to experts; the hide has to be taken off at once. The skins are taken from the field to the salt-house, where they stay for two or three weeks, being pickled; after this they are taken and rolled into bundles of two skins in each package, with the hairy sides out and lightly corded. In this state they go by steamer to San Francisco, where they are counted for the tax, and from thence they are shipped to London.

In a series of illustrative and supplemental notes to this volume, there are a number of very interesting details as to the Russian Seal Islands; as to the Fauna and Flora of the Priblyov Group; a digest of the data in regard to the fur seal rookeries of the South Atlantic and Pacific, and the number of skins taken therefrom. There is a translation of Veniaminov's account of the Russian seal industry at the Priblyovs, 1842 ; a meteorological abstract for the months from September, 1872, to April, I873, which was an unusually severe winter; and a history of the organisation and regulations of the Alaskan Commercial Company, under whose excellent management the sealskin trade is now carried on. In concluding a necessarily somewhat brief notice of this excellent monograph, we would congratulate $\mathrm{Mr}$ Commissioner Spencer Baird on being the means of obtaining for men of science and of commerce so much valuable information, and we can scarcely give too much praise to Mr. Henry M. Elliott for his most artistic and praiseworthy history of the most interesting of all Pinnipeds.

\section{A DYNAMOMETER FOR ALTERNATING CURRENTS OF MODERATE STRENGTH}

$T \mathrm{HE}$ object of this instrument, which I had the pleasure of bringing before the Physical Society at their Oxford meeting, is chiefly medical. But it occurred to 
me that a few details, mainly constructive, might prove of interest. It was suggested by Mr. Preece, in consequence of a statement made by ne in a paper on "Measurement in the Medical Application of Electricity," read before the Society of Telegraph Engineers. This statement was to the effect that some difficulty still existed in the trustworthy estimation of induction currents of medium strength, such as are habitually used for physiological and therapeutical purposes. The French International Conmission had only imperfectly remedied the defi:iency by recommending the universal adoption of a particular pattern of induction coil made by a single German firm, and arbitrarily graduated to a "sledge" apparatus. Mr. Preece thought that a dynamometer, which may be regarded as a galvanometer of which the moving magnet is replaced by a suspended coil introduced into the circuit, would answer the purpose ; since the deflection of the coil is in one uniform direction, although the currents traversing the circuit are alternate. This very practical hint seemed to offer a prospect of obtaining accuracy in a department of science in which it is much needed. But on examining existing dynamometers I found only Weber's original instrument, which, in spite of it 3 immease value, is fitted only for a well-appointed laboratory, and another, małe by Messrs. Siemens for the measurement of very intense electric light currents, which erred on the opposite side of deficient delicacy. The dynamometer of Messrs. Siemens, shown at the French International Exhibition, by means of which the alternating currents of telephones were demonstrated, was probably in the same category, though neither I, nor the president of the Physical Society could obtain any exact details of its internal arrangements.

An electrodynamic balance, described in the 4 nnalen der Physik in I88I by Helmholtz, comes somewhat closer to the requirements of the case, but this, like that of Weber, is a delicate apparatus, difficult of transportation. It might, however, prove excellent as a means of calibrating a less perfect and absolute, but more handy instrument, such as that I was in search of.

Another form of dynamometer had been incidentally named to me by Mr. Ayrton, of his invention, in which the moving coil is replaced by a piece of soft iron which becomes magnetic during the passage of the current. Of this also further details were wanting.

I therefore attempted to make one for myself by the usual method of suspending a coil of wire from two silk fibres within a fixed coil, bringing its two ends to mercury contacts at the lower part, and joining all up in one circuit. Two defects at once appeared. I. The coil of copper wire was far too heavy to move with the small currents at my disposal; and when it did swing, it continued to oscillate slowly for an unlimited time, giving no satisfactory reading. 2. The mercury contacts caused so much friction as absolutely to stop all motion whatever.

It was therefore obvious that (I) a light coil, and (2) a sensitive bifilar suspension were needed. Both of these must have a fairly high electrical conductivity. The second of these desiderata may be dismissed first. I found at the gold lace shops bobbins of silver-gilt wire, in which the gold is drawn over the silver in manufacture; not merely plated on. These two combined have a diameter of $\frac{1}{50}$ of an inch; which is exactly that of the finest platinum wire commercially made. But whereas the resistance of I metre of the latter is $62^{\circ} 2 \mathrm{ohms}$, that of the former is only $9^{\circ} 8$ ohms. An induction shock from Dubois-Reymond's apparatus passed through a metre of this wire has such strength, that I do not wish to try it again, nor should $I$ venture to administer it to an invalid.

It occurred to me that (I) the light coil might be obtained by using fine alu ninium wire covered with silk. Messrs. Johnson and Matthey, with their usual courtesy, drew this for me specially, to a diameter of I-rooth of an inch, or even less, ${ }^{1}$ and Mr. Rickards, of Derby, completed the operation.

By winding this on a mandril, tying the ring thus obtained with silk threats, and immersing in photographic amber varnish, which I find much less dense, and as good an insulator as Shellac, I obtain a coil composed entirely of metal and silk, which is at once rigid, light, and conductive. One of these, of $1 \cdot 25$ inches internal diamater, not of very fine wire, contains forty two turns of wire in five layers, its length thus being over four yards. It weighs 6.25 grammes, less than 100 grains, its resistance is about half an ohm.

On suspending this light coil from two threads of the silver-gold wire named above, I found its deflections considerable, and easily measured, even with moderate currents. It could easily be made "dead-beat." The bifilar couple was varied by giving the suspending points a sliding motion to and from each other. By also fashioning the suspensions in the form of light vertical springs, the two threads were kept at an approximately equal tension.

Aluminium appears to offer great advantages for employment in such functions as these. It is said in Watt's "Dictionary," that "the electric conducting power of aluminium is eight times as great as that of iron, and about equal to that of silver," where probably the comparison is intended to be made with equal weights, and not volumes. But even if it were lower, it would be abundantly sufficient for the purpose named, as the currents are of high tension, and as the resistance need not be materially less than that of the suspending wires given above. Its specific heat is very great, so that moderate changes of temperature affect it but little. This property might render it valuable for the fabrication of resistance coils.

It was stated at the meeting that this metal had been tried by Messrs. Siemens, but given up in consequence of the failure of connection in the ends of the aluminium wire. This difficulty I have not found, probably in consequence of the high tension, and also from the fact that the contacts are between gold and aluminium, both stable substances. In any case the difficulty could be overcome by making a gripping contact with a light clamp, such as is already used in watchwork. Nor can Messrs. Siemens' unsuccessful attempt for other purposes be, I think, considered as a distinct anticipation of this. The mechanical advantage of such a light coil in diminishing moment of inertia, and in reducing the force of the bifilar couple, can hardly be denied on theoretical grounds, and is, indeed, borne out by experiment.

W. H. STONE

\section{MATHEMATICS AT THE FOHNS HOPKINS UNIVERSITY}

$\mathrm{F}$ ROM time to time we receive copies of the University Circular. From two now before us, we make a few extracts, which will serve to show what this young but promising University has done (or attempted to do) in the session I88I-82. The students have been thirty-two in number; of these, twenty followed advanced and University courses, and twelve pursued collegiate courses. Supreme over the department presides Prof. Sylvester, F.R.S., who, besides editing the American Fournal of Mathematics and reading papers at the Mathematical Seminary (similar in its character to our own London Mathematical Society), has delivered two courses of lectures-one on the Theory of Numbers (and in especial on an extension of Tchebycheff's theory concerning Prime Number $)$, the other on a new theory of universal multiple algebra.

This session on the invitation of the Trustees, Prof. Cayley was called in as amicus curia, and arrived at

$\mathbf{I}$ The finest wire has not yet been measured in the microscope ; it passes through the smallest hole of the B.W.G., No. 80 . 